\title{
A escrita nas práticas de letramento acadêmico
}

\author{
Writing in academic literacy practices
}

Marildes Marinho*

Universidade Federal de Minas Gerais

\begin{abstract}
RESUMO: São inúmeros os trabalhos sobre o ensino-aprendizagem da escrita no ensino fundamental e médio. No entanto, a escrita acadêmica ainda não tem recebido a merecida atenção, no Brasil. Serão analisados aqui alguns elementos próprios das condições de produção de escrita de alunos de um curso de graduação. A concepção bakhtiniana, para a qual o domínio de um gênero é um comportamento social, articulada com uma abordagem etnográfica, delineia o referencial teórico-metodológico principal. Abordar o texto etnograficamente significa tratá-lo como um traço ou um elemento de uma situação social, que inclui igualmente os valores, regras, significados e atitudes, assim como modelos de comportamento dos participantes da interação. Conclui-se que o envolvimento da universidade com o ensino-aprendizagem da escrita acadêmica demanda pesquisas sobre habilidades e competências linguísticas e também sobre fundamentos e estratégias que permitam refazer princípios e crenças que têm levado nossos alunos a uma relação "tímida", "deficiente", "inadequada" e tensa com as práticas acadêmicas letradas.
\end{abstract}

PALAVRAS CHAVE: Letramento acadêmico; escrita; etnografia.

ABSTRACT: There are several researches about the process of teaching and learning writing in basic education. However, in Brazil academic writing hasn't received the deserved attention yet. In this article, some elements that are intrinsic to the written production conditions of students in undergraduate course offered by one university will be analysed. Bakhtin's conception, in which the control of a genre is seen as a social behavior, associated with an ethnographic approach, constitute the main theoretical reference to this study. Approaching the text ethnographically means to treat it as a feature or as an element from a social situation, which includes the values, the rules, the meanings, the attitudes, as well as the models of behavior of the participants that take part in the interaction. The conclusion is that the commitment of the university with teaching and learning academic writing requires researches about the linguistic skills and competences, and also about the foundations and strategies that allow us to rebuild the principles and beliefs that have contributed to the construction of students' relation with academic literacy practices often considered 'shy', 'deficient', 'inadequate', and 'tense'. KEYWORDS: Academic literacies; writing; teaching and learning

*marildesmarinho@gmail.com 


\title{
Apresentação
}

\author{
Lembro-me de um professor, do primeiro período, que \\ sempre dizia que nós não precisávamos necessariamente \\ concordar em tudo com o autor que lemos e que o nosso \\ papel era questionar aquilo que estava escrito. Desde então \\ acredito que tenho um sério problema, pois não consegui \\ discordar, até hoje, de nenhum autor que li. \\ (Depoimento de uma aluna de graduação, 2008)
}

O interesse principal deste trabalho é discutir as relações de alunos com a escrita em cursos de graduação ou com as práticas acadêmicas de letramento. As constantes queixas de professores universitários (e dos próprios alunos) de que os alunos têm dificuldade na leitura e na produção de textos acadêmicos nos alertam para a necessidade de transformar essas queixas em propostas de ensino e de pesquisa. Buscando, então, articular ensino e pesquisa, interessa-me, mais especificamente, analisar práticas acadêmicas em contextos de formação de professores, mais especificamente na formação inicial do curso de Pedagogia.

As consideraçôes aqui apresentadas se apoiam também em projetos de ensino e de pesquisa, envolvendo a leitura e a escrita, em cursos de formação inicial (graduação) e continuada de professores, de pós-graduação, mais especificamente, na disciplina de Leitura e Produção de Gêneros Acadêmicos em Educação - criada em 2004, em currículos de graduação e de pós-graduação. O propósito central desses projetos envolve o trabalho com uma diversidade de gêneros discursivos. Um deles é a produção de textos memorialísticos como estratégia de formação e de pesquisa. (Ver MARINHO, 2004; MARTINS, 2005; MARINHO; MACHADO; COELHO; GOMES, 2009)

Uma pergunta destinada às instituiçôes acadêmicas de formação de professores pode ser o início de uma resposta a essas queixas: como instituir, nos cursos de formação docente, práticas de escrita, que possam funcionar, simultaneamente, como estratégia de formação e de pesquisa para se compreender as condiçōes de formação do professor, supondo que ele deva se inserir cada vez mais em práticas de escrita e também capacitar e mediar seus alunos nos processos de inserção nessas práticas?

Se muitos trabalhos já se interrogaram sobre as estratégias e disposições leitoras do professor, parece razoável que nos interessemos também por uma outra interface da relação com a escrita, o lugar de autoria na interação com textos escritos: o que, para que e como se escreve nos cursos de formação? Quais são as disposiçōes dos professores formadores e dos alunos-professores 
nas relações mediadas pela escrita nesses contextos? Como instituir gêneros e estratégias que possibilitem constituir lugares de autoria para os alunos (futuros professores)? O que podem nos revelar os textos produzidos nessas circunstâncias de enunciação? Essas perguntas têm subjacentes pressupostos, sustentados por uma concepção enunciativa da linguagem que, numa combinação com uma perspectiva etnográfica de investigação, desejam compreender os gêneros como um comportamento social.

Orientado por essas perguntas, este artigo está organizado em três momentos. Na segunda e na terceira seções, contextualiza-se a temática, com a identificação de alguns pressupostos que têm orientado um certo modo de pensar e de observar a relação dos estudantes universitários com a escrita acadêmica. Em seguida - na quarta seção - são levantados alguns argumentos para reivindicar a necessidade de se pesquisar a relação dos professores com a escrita no desempenho da sua profissão docente. Algumas possibilidades teórico-metodológicas de abordagem do gênero acadêmico são indicadas na quinta seção, entre elas a etnografia, que é a escolha aqui adotada. Nessa perspectiva, o leitor encontrará, na sexta e na sétima seçôes, a análise de um evento de letramento acadêmico, que ocorre em uma sala de aula, em que os alunos são orientados a produzir uma resenha. $\mathrm{O}$ artigo sugere a necessidade de se desconstruir a concepção de um gênero cristalizado nas salas de aula das universidades, o "trabalho", por acreditar que as concepções de texto e de discurso subjacentes ao "trabalho" das disciplinas do currículo de graduação tendem a transformar a escrita dos estudantes de graduação em um modelo engessado de texto escolar. Sob essa concepção, as estratégias enunciativas desses textos poderão não corresponder nem às formas composicionais, nem ao estilo e nem às diversas funções e possibilidades que o domínio discursivo das ciências humanas propiciam. Para concluir, enfatiza-se a relevância de uma descrição etnográfica dos usos da escrita nos cursos de graduação, assim como a importância de que sejam atribuídas funções sócio-comunicativas à produção de textos que, de fato, permitam aos alunos desenvolver suas habilidades de escrita, assim como usufruir dela como um meio de aprender e de construir conhecimento.

\section{A experiência como um fator determinante do aprendizado de um gênero discursivo}

São inúmeros os trabalhos que discutem o ensino-aprendizado da leitura e da escrita no ensino fundamental e médio, no Brasil. Ao contrário, a escrita acadêmica não tem recebido a merecida atenção na universidade, seja do ponto 
de vista do ensino, seja como objeto de pesquisa. Em universidades estrangeiras, são muitas as publicações voltadas para o ensino e a pesquisa sobre a leitura e a escrita nos cursos de graduação e de pós-graduação, enquanto aqui essa produção ainda é tímida. Kavakama (2001) lembra que as universidades brasileiras tiveram grande influência do modelo americano de universidade, mas não herdaram desse modelo a prática de pesquisa e ensino da escrita que lhes garante a produção e a circulação do conhecimento.

Uma das prováveis justificativas para essa lacuna pode ser a crença (subjacente aos discursos de senso comum e aos currículos) no princípio de que se aprende a ler e a escrever (não importa qual seja o gênero) no ensino fundamental e médio. Aos professores universitários, costuma causar estranhamento o fato de encontrar alunos pouco familiarizados com a leitura e a produção de gêneros que sustentam as suas aulas e outros eventos próprios à vida acadêmica. Numa discussão de reforma curricular de um curso de Pedagogia, por exemplo, quando foi criada uma disciplina sobre Leitura e Produção de Gêneros Acadêmicos, alguns professores, inicialmente, questionaram a importância dessa disciplina, por considerarem que o aluno aprovado no vestibular teria sido avaliado nas suas habilidades de leitura e de escrita e, consequentemente, estaria apto a ler e a escrever com propriedade e familiaridade os textos acadêmicos. ${ }^{1}$

Sabemos, no entanto, que os gêneros acadêmicos não constituem conteúdo e nem práticas preferenciais nas escolas de ensino fundamental médio. A leitura e a escrita de gêneros de referência na academia -artigos, teses, monografias, dissertações, resenhas acadêmicas, entre outros - são realizadas, de preferência, na universidade, porque é nessa instituição que são produzidos, por necessidades próprias, esses gêneros. Neste trabalho, ao se optar por uma concepção de linguagem e, principalmente, de gênero, tal como formuladas por Bakhtin, torna-se mais coerente esperar e aceitar que os alunos universitários se familiarizem e aprendam a ler e a escrever os gêneros acadêmicos, sobretudo, na instituição e nas esferas do conhecimento em que são constituídos, portanto, quando se inserem nas práticas de escrita universitária. Consequentemente, parece necessário incluir esse conteúdo nos currículos e nas pesquisas.

\footnotetext{
${ }^{1}$ É importante ressaltar que, por não ser objeto deste trabalho, não tratamos dos gêneros orais acadêmicos (a aula, a conferência, o seminário, a entrevista, a defesa de monografias, dissertaçôes, teses, por exemplo), mas esses também são aprendidos na universidade e também oferecem grandes desafios aos alunos.
} 
Bakhtin, um nome de referência nos estudos contemporâneos sobre a linguagem, numa perspectiva sócio-cultural enunciativa, nos dá um forte e conhecido argumento para se repensar uma certa maneira com que se lida com as dificuldades de leitura e de escrita dos alunos na universidade: o domínio de um gênero é um comportamento social. Isso significa que é possível ter um bom domínio da língua, mas ser inexperiente na atividade de moldar os gêneros, de administrar a interação, a tomada de turnos, etc. A experiência é algo constitutivo da prática nas comunidades que fazem uso de determinados gêneros, tornando-se, assim, condição indispensável para uma interação verbal bem-sucedida. Assegura o autor que "são muitas as pessoas que, dominando magnificamente a língua, sentem-se logo desamparadas em certas esferas da comunicação verbal, precisamente pelo fato de não dominarem, na prática, as formas do gênero de uma dada esfera." (BAKHTIN, 1997, p. 303). Ele exemplifica ainda com uma situação que pode ser, de maneira invertida, a mesma em que se encontra a maioria de nossos alunos na universidade: "Não é raro o homem que domina perfeitamente a fala numa esfera da comunicação cultural, saber fazer uma explanação, travar uma discussão científica, intervir a respeito de problemas sociais, calar-se ou intervir de uma maneira muito desajeitada numa conversa social" (op. cit., p. 303).

Relembra também Bakhtin que essa dificuldade não se trata de "uma pobreza de vocabulário ou de estilo (numa acepção abstrata)" mas, sim, de uma inexperiência no domínio desses gêneros da conversa social. Embora o autor garanta que, nesses gêneros da conversa social, a composição seja muito simples, a dificuldade do indivíduo encontra-se numa "falta de conhecimento do todo do enunciado que o faz inapto para moldar com facilidade e prontidão a sua fala e determinadas formas estilísticas e composicionais; por inexperiência de tomar a palavra no momento certo, de começar e terminar no tempo correto." (op. cit., p. 303-4, grifos meus). E onde estariam, pois, as comunidades de práticas $^{2}$ do gênero acadêmico, para esses estudantes, senão nas universidades?

É, todavia, compreensível que também os alunos, de maneira involuntária ou inconsciente, compartilhem dessa crença, porque as experiências adquiridas forjaram essas concepçóes. São várias as situaçóes

\footnotetext{
${ }^{2}$ Lave and Wenger (1991) Wenger (1998) desenvolveram o conceito de comunidades de práticas como uma idéia central na discussão sobre os processos de aprendizagem, nos quais a experiência é um fator primordial no aprendizado contextualizado. Esse referencial promete incursōes promissoras ainda a serem feitas. Ver também Barton and Tusting, 2005.
} 
reveladoras dessa adesão, por exemplo, ao reagirem negativamente quando seus professores, na universidade, avaliam os seus textos e indicam inadequações e o desconhecimento de estratégias discursivas próprias ao texto acadêmico. Isso ocorre principalmente com alunos que foram considerados bem-sucedidos na sua relação com a escrita, durante a sua trajetória escolar prévia.

Sintomático é o caso de uma aluna que declarou ter chorado intensamente por decepção quando recebeu de um professor a sua resenha com correções, sugestôes e com uma nota equivalente a setenta por cento dos pontos destinados a essa tarefa. Inicialmente supus que o incômodo dessa aluna se explicasse, como costuma ocorrer, em função da nota, considerada baixa por ela. Mas esse professor dava aos alunos a oportunidade de refazer o texto e, consequentemente, ele refazia também a nota. Sugeri, então, a ela que trouxesse a resenha com as intromissóes do professor, para tentar compreender o que teria ocorrido. Ao final, ela se convenceu de que, de fato, as sugestôes do professor eram muito boas e que a escrita acadêmica é bem diferente daquelas que ela costumava realizar com sucesso na escola quando era adolescente.

Essa situação foi muito rica e esclarecedora para ela e para os colegas que participaram da discussão, pois foi possível avaliar e explicitar vários aspectos relativos ao funcionamento de um gênero discursivo, em particular da resenha acadêmica. Um desses aspectos é o lugar do autor, nessa enunciação. O resenhista ocupa um lugar de autoridade, de alguém que conhece bem o assunto da obra em questão, pois, em geral, quem escreve resenhas críticas são especialistas no assunto, algumas vezes mais experientes do que o próprio autor da obra resenhada. E, ao contrário, esse não é o lugar ocupado por um aluno quando produz uma resenha. No caso envolvendo essa aluna, tratava-se de uma obra de História da Educação, com uma temática nova para ela, que estava, na época do episódio, entrando na universidade. Se somarmos a isso o fato de que na outra ponta dessa interação pela escrita encontra-se um leitor especialista (o professor de História da Educação), podemos supor que essa é, por condição, uma relação tensa para o aluno. O aluno é aprendiz de uma escrita, não tem um lugar legítimo, de autoridade, na maioria dos gêneros que produz. É possível que nós, professores, projetemos nesses textos dos alunos expectativas pouco compatíveis com as suas experiências e conhecimentos sobre esses gêneros.

A validação e a legitimação da leitura crítica de uma obra se sustentam, sobretudo, pelo nome do autor, que traz consigo uma titulação e uma instituição. Isso não quer dizer, obviamente, que essa atividade, muitas vezes fictícia e artificial - pelas próprias condições de produção de alguns textos, em algumas 
situações escolares - não tenha relevância, na sala de aula. No entanto, mais pertinência e relevância terão se essa artificialidade for diminuída, de maneira que os textos produzidos pelos alunos ganhem uma função social própria, transformando-se em uma estratégia de troca, de partilha e de debate dos próprios textos que escrevem e daqueles que leem.

Outro aspecto decorrente desse lugar do autor, também relacionado ao lugar de autoria foi o atendimento a uma estrutura prototípica. Além de apresentar a obra, de resumir, selecionando aspectos mais relevantes, espera-se que o resenhista avalie, se posicione em relação ao conteúdo do livro. E esse posicionamento precisa ser muito bem argumentado, justificado. Isso quer dizer que a elaboração de uma resenha envolve também um lugar de leitor, que, nesse caso, realiza uma leitura também nova, nos textos, gêneros e nas estratégias. Por isso ler e escrever são atividades complementares, em que apenas se alterna o lugar de proeminência de uma delas, em um determinado momento da atividade de linguagem.

\section{Uma relação tensa com os gêneros acadêmicos na universidade}

O depoimento de uma aluna desse curso de Pedagogia exemplifica com perspicácia e intuição essa complexidade e tensão envolvidas nesse novo universo letrado a que terão acesso esses estudantes:

A entrada na universidade foi, portanto, muito difícil, principalmente em relação à leitura de textos específicos de sociologia, política e psicologia, em que li autores como Marshall Berman, Talcott Parsons, Pierre Bourdieu e Carlos Lerena, sendo este último em espanhol. Possuo grande dificuldade de interpretação de textos acadêmicos, acredito que principalmente pela utilização nesses textos de termos técnicos e vocabulário muito rebuscado. Lembro-me de um professor, do primeiro período, que sempre dizia que nós não precisávamos necessariamente concordar em tudo com autor que lemos e que o nosso papel era questionar aquilo que estava escrito. Desde então acredito que tenho um sério problema, pois não consegui discordar, até hoje, de nenhum autor que li (Depoimento aluna Pedagogia, 2008, grifos meus).

Em primeiro lugar, destaca-se a lista de autores e textos que lhes são apresentados aos quais poderíamos juntar tantos outros, Marx, Bakhtin, Vigotsky, Geertz... Que aluno de ensino médio, por mais treinado que seja no uso da língua, teria facilidade em ler Marshall Berman, Talcott Parsons, Pierre Bourdieu e Carlos Lerena? Em segundo, a leitura desses textos não depende 
de um conhecimento de "termos técnicos" e de "vocabulário rebuscado", como supõe a aluna. Depende de muito mais do que isso. O leitor-modelo desses textos são especialistas, pertencentes a uma comunidade de leitores, pessoas que transitam nesse campo de conhecimento, que contam com conhecimentos prévios e estratégias de estabelecer relaçôes interdiscursivas, intertextuais e de situar o texto em relação à obra do autor, ao contexto histórico, ao campo disciplinar, etc. A rede discursiva em que se inserem esses autores e seus leitores contemporâneos exige um laborioso trabalho e um tempo de convivência que atravessa todo o curso de graduação, não tendo um ponto final para aqueles que se aventuram na trajetória acadêmica de mestrado, doutorado e pesquisas.

Logo, como poderia um estudante de graduação discordar de uma autoridade científica de um autor, arregimentando, do seu lado, argumentos de autoridade?

O discurso acadêmico se sustenta por estratégias elaboradas de erudição pouco compreensíveis e usuais para um leigo. Grafton (1998), em As origens trágicas da erudição: uma história das notas de rodapé, analisa a complexidade e o poder dos efeitos produzidos por de um dos dispositivos do discurso científico, ou da erudição. O leitor encontrará nessa obra inúmeras situaçōes e metáforas estilhaçantes que descortinam significados pouco visíveis na rotina da produção do discurso erudito, produzido por e para um grupo seleto, para os pares:

$\mathrm{Na}$ Itália, a nota opera muitas vezes por omissão: o fato mesmo de não citar tal ou tal obra pode revestir a significação polêmica, de uma damnatio memoriae que o círculo de interessados decodificará imediatamente. (...). Mas o círculo daqueles que sabem ler os silêncios é evidentemente estreito. Ora o autor se dirige de uma parte à pequena comunidade de especialistas entendidos nesse idioma, e de outra parte àquela de historiadores em geral, outros leitores que por acaso lerão a revista... Somente aqueles que assimilaram as chaves do código de citação - um código, com certeza, mutante - saberão pesar essas pesadas ausências. Para os outros, essas mesmas notas serão informativas (17-18. Grifos meus).

Parece importante, então, refletirmos sobre a violência simbólica presente nessas relações acadêmicas de ensino-aprendizagem. Schitine (2003) descreve situações exemplares das representações que professores universitários fazem dos alunos e de suas relações com o texto acadêmico na sala de aula. As brincadeiras, os chistes são sintomas dessa relação, muitas vezes tensa e difícil, tanto para os alunos quanto para os professores: 
Às vezes, ironizavam a dificuldade de compreensão dos alunos dos textos propostos: um professor, sentindo que os alunos não estavam entendendo um texto, fez o seguinte comentário: "as leituras possibilitam para alguns saber onde está a fumaça. Ele tenta descobrir o fogo, que está fácil de ser encontrado. Outros não percebem nem onde está o fogo.” (Comentário de um professor, em uma aula, na universidade)

Às vezes, ironizavam a falta de leitura dos alunos: um professor sempre perguntava por leitura de livros diversos, mas quase sempre os alunos não os tinham lido: "já leram Adão e Eva de Eça de Queiroz? Não? Deveriam ler, mesmo sem figurinha." [...] É preciso ler, para saber, pelo menos, em qual árvore que o ninho está. Descobrir o ninho." (Comentário de um professor, em uma aula, na universidade)

Ainda como desdobramento da crença no domínio da língua como garantia para o domínio do gênero, manifesta-se outro pressuposto: um trabalho de ensino-aprendizagem da escrita acadêmica é uma estratégia compensatória, interessada em oferecer aos alunos, que "têm dificuldades de leitura e de escrita", a oportunidade de recompor lacunas de um processo de escolarização supostamente deficitário, de aprender aquilo que deveriam ter aprendido antes de entrar na universidade. Por meio de estratégias eufemizadoras ou tacitamente naturalizadas, esse é um dos campos onde também se produzem estigmas que afetam nossos alunos, na universidade. ${ }^{3}$ Em geral, quando são chamados a refletir sobre a sua relação com a escrita, ${ }^{4}$ eles não consideram o fato de ser razoavelmente natural que não tenham um domínio desses gêneros discursivos. O comum é afirmam sempre que "têm dificuldade, que não sabem ler e escrever", reforçando uma atitude autodiscriminatória, já que deveriam saber, mas não sabem. No depoimento abaixo, da mesma aluna citada anteriormente, ela deixa sinais claros de como pode ser mesmo torturante o aprendizado da escrita, num curso de graduação:

Um curso na área das ciências humanas exige muita produção escrita e escrever um texto de no mínimo dez páginas, como é muitas vezes pedido a nós, é uma grande tortura. Geralmente necessito de aproximadamente duas horas para começar a redigir um texto, talvez

\footnotetext{
${ }^{3}$ Dados do autor.

${ }^{4}$ Uma das primeiras atividades do curso de Leitura e Produção de Gêneros Acadêmicos em Educação é a reflexão sobre a relação desses alunos com a escrita. Em seguida, desenvolve-se uma reflexão mais sistematizada sobre os discursos e gêneros acadêmicos, numa perspectiva da enunciação, da análise do discurso francesa.
} 
esse seja o meu principal problema, acredito que meu vocabulário também não seja suficientemente rico para redigir textos acadêmicos. Além disso, todas as vezes que escrevo um texto, penso que posso aperfeiçoá-lo, mas na maioria das vezes acabo me atrapalhando, perco muito tempo e ao fim de um processo não consigo fazer modificações positivas. Transmitir para o texto escrito as minhas idéias também é uma grande dificuldade. Questóes como a coerência e a argumentação me preocupam, pois já perdi alguns pontos em trabalhos escritos pela falta dessas características. (Depoimento de aluna do Curso de Pedagogia, 2008)

Essa dificuldade ou lacuna de saber costuma ser simplificada por outra crença subjacente aos discursos correntes segundo a qual basta aprender (e principalmente treinar) um conjunto de estratégias textuais, de conteúdos gramaticais, de regras e convençôes típicas do texto acadêmico, para que essas dificuldades sejam resolvidas.

Diante desse cenário, podemos inferir que um dos desafios da proposta aqui apresentada ou de outras semelhantes é o de desfazer princípios, crenças, mal entendidos que sustentam e propiciam uma relação "tímida", "deficiente" "inadequada" dos nossos alunos com as práticas acadêmicas sustentadas pela escrita. $^{5}$

Felizmente, esse cenário está mudando. Depois de alguns investimentos nesse campo, percebo que um maior número de colegas na universidade está convencido de que é necessário cuidar desse objeto de ensino e de pesquisa, mesmo porque esse investimento propiciará uma economia do trabalho desses professores quanto ao ensino de estratégias de leitura e de escrita aos nossos alunos; trabalho esse que vem sendo feito muitas vezes de forma assistemática e intuitiva. Várias universidades vêm incluindo esse conteúdo nos currículos ou em atividades extracurriculares. Tem crescido significativamente o mercado editorial de livros para auxiliar os jovens pesquisadores e estudantes universitários nas suas atividades de escrita universitária. O que não quer dizer, obviamente, que essas publicações sejam bem-sucedidas. Uma pesquisa nos currículos de cursos de graduação vai, provavelmente, nos indicar a inclusão desse conteúdo. Também a internet vem se tornando um espaço para auxiliar, principalmente iniciantes, a escrever seus trabalhos acadêmicos. Tanto os sites quanto as crescentes publicaçóes podem se tornar objetos promissores para a pesquisa nesse campo.

${ }^{5}$ Ver dissertação de mestrado de Schitine (2003), que analisa a relação de professoras com a escrita em um curso de pós-graduação Lato sensu. 


\section{Gêneros acadêmicos nas práticas de formação de professores}

Embora estejamos utilizando correntemente o termo gênero acadêmico, afinal o que ele significa? Para responder a essa pergunta, não bastaria enumerar uma lista de gêneros e tipos de textos já legitimados, tais como tese, dissertação, monografia, artigo, ensaio, resenha, resumo, entre outros. Mais uma vez coerente com a afirmação de que pouco se sabe sobre a escrita na academia, é necessário pesquisar sobre essas práticas para compreender quais gêneros produzimos e como produzimos, quando escrevemos, em contextos acadêmicos diversos? Por detrás desses nomes já conhecidos, podem se esconder concepções, formas e usos distintos.

Creme e Lea (2003, p. 27) argumentam que, "normalmente, quando pensamos numa escrita na universidade, pensamos em como escrever um ensaio". Mas sabemos que o ensaio, ou artigo, é um dos textos que escrevemos, pois somos convidados a escrever sumários, sínteses, relatórios, comentários, avaliaçōes, arguiçōes, sobre assuntos de uma determinada área e de uma perspectiva específica, por exemplo, num estilo jornalístico, didático, etc. Uma tese produzida na área de medicina é bastante diferente de uma tese produzida na área de educação, da mesma forma variam todos esses outros gêneros anteriormente citados, caso sejam produzidos por pesquisadores da área de letras, de educação, das ciências sociais e tantas outras áreas possíveis. Os alunos do curso de graduação engenharia, em geral, estudam em manuais didáticos específicos e a produção acadêmica na área ocorre em periódicos em língua inglesa ou alemã. Ou seja, a construção dos diferentes objetos disciplinares se traduz também por diferentes modos de linguagem, de enunciação, de dispositivos discursivos. Aqui também podemos chamar Bakhtin (1997), quando nos diz que os gêneros são forma relativamente estáveis, e creio que poderemos - numa análise mais minuciosa das formas composicionais e das práticas culturais - prever que eles são muito mais relativamente estáveis do que imaginamos.

Neste trabalho, as práticas de letramento acadêmico se situam no campo da educação, de profissionais do ensino fundamental, no qual muito já se discutiu e mais ainda se pode discutir sobre o professor e suas "disposiçôes letradas" ou as suas condições de acesso ao "mundo da escrita". Essa produção tem se voltado mais especificamente para as práticas de leitura do professor, e também é recente o olhar sobre o lugar de autoria, dos significados da produção, e não apenas da recepção de textos escritos, na vida do professor. 

muitas dúvidas sobre a importância e a necessidade de implementar políticas para que os professores participem de determinadas práticas de leitura, das quais vêm historicamente sendo excluídos. Nos cursos de formação, a leitura é o vetor principal. Ao contrário, não parece fácil imaginar que políticas seriam necessárias, desejáveis ou pertinentes, quando se trata de pensar essa identidade profissional por meio do ato de escritura. Nós, acadêmicos, gastamos grande parte do nosso tempo de trabalho lendo e escrevendo. Não lemos e escrevemos necessariamente porque gostamos, mas porque trabalhamos lendo e escrevendo; isso faz parte do nosso contrato de trabalho, e, hoje, cada vez mais temos que prestar conta, em números, das nossas atividades que se expressam por meio de relatórios, projetos, artigos, livros, trabalhos em anais de congressos, etc.

Voltando nosso olhar para o professor do ensino fundamental e médio, perguntamos: quais são as condições de trabalho quando pensamos nas atividades que ele realiza na sua profissão docente? Há um campo de pesquisa sobre a escrita no trabalho, razoavelmente bem constituído por ergônomos, linguistas e sociólogos. ${ }^{6}$ Em que medida os professores têm se tornado foco dessas investigaçōes? Qual o lugar da escrita no exercício da sua profissão e na sua vida ordinária? Sabemos muito pouco sobre o lugar que a escrita ocupa no exercício da profissão docente.

Enfim, depois de algum tempo ouvindo queixas sobre "o professor que não lê" e o "professor que não escreve", percebe-se um movimento em direção a açōes propositivas no campo da pesquisa e da formação de professores. Se alimentamos, de alguma forma, esses discursos, por que não nos interrogamos sobre o que fazemos ou que propomos a esses professores, nos cursos de formação, quando se trata de trabalhar com a leitura e com a escrita? Se há problemas com esse professor, em que medidas as instituições de formação também são responsáveis por eles? A partir de então, implementar projetos de ensino e pesquisa focalizando a leitura e a escrita na formação de professores, buscando refletir sobre as disposiçôes e práticas de professores, nesses contextos de formação, tem sido nosso objetivo. Interessa-nos não só uma análise e compreensão da escrita, dos textos produzidos (suas regras, valores, significados) mas também as suas condições de produção, as disposições, crenças e valores atribuídos por esses sujeitos à escrita.

${ }^{6}$ Fabre, 1997; Lahire,1993; Boutet, 1993a, 1993b; Fraenkel, 2001. 


\section{A perspectiva etnográfica da pesquisa sobre letramento acadêmico}

Existem várias possibilidades ou paradigmas para se abordar os gêneros. Flowerdew (2006), na apresentação de um livro, organizado por ele e cujo título é Academic Discourse, descreve quatro deles, provavelmente os mais utilizados nas pesquisas sobre o discurso acadêmico: análise de gêneros (Swales), retórica contrastiva, análise de corpus e abordagem etnográfica. Ele nos alerta, no entanto, que há outras maneiras (também importantes) de se realizar esse tipo de pesquisa, por exemplo, o processo psicolinguístico envolvido na produção e recepção de textos (VAN DIJK; KINTSCH, 1983; OLSEN; HUCKIN, 1990; ROST, 1994, TAUROZA; ALLISON, 1994; FLOWERDEW; TAUROZA, 1995), as abordagens diacrônicas (BAZERMAN, 1988; ATKINSON, 1992; GUNNARSSON et al., 1997); Análise crítica do discurso (BOURDIEU et al., 1994; PENNYCOOK, 1996; CANAGARAJAH, 1997), além da perspectiva hallidayana do gênero. Para Flowerdew (p.4), a etnografia é talvez o menos conhecido paradigma de pesquisa discutido no campo do discurso acadêmico. Essa abordagem privilegia a análise de textos, falados ou escritos, focalizando o texto etnograficamente como "um traço de uma situação social, que inclui igualmente os valores, regras, significados e atitudes, e modelos de comportamento dos participantes, ou produtores e recebedores de textos. (FLOWERDEW; MILLER, 1996; VAN LIER, 1988; CANDLIN; PLUM, 1999.)”. A metodologia etnográfica enfatiza a observação direta, a entrevista, e outros modos de análise do contexto social, em adição à análise do texto.

Um importante aspecto a ser considerado numa pesquisa dessa natureza são as relações de poder envolvidas nas relações mediadas pela linguagem (e certamente nas instituiçóes acadêmicas), relaçóes essas amplamente analisadas pelas correntes da análise do discurso francesa e por estudos sociológicos da linguagem.

Creio que, para os nossos objetivos na educação, necessitamos de trabalhos que abordem o discurso acadêmico nas suas diversas perspectivas, podendo privilegiar como foco central, por interesses específicos, um referencial teórico, mas não perdendo de vista uma perspectiva integradora das diferentes facetas que compõem as práticas de letramento. A perspectiva etnográfica nos permite conhecer os usos e funções da escrita do letramento - o quê, como e para quê-, as disposições e expectativas. Uma perspectiva da análise linguística dos gêneros nos oferece subsídios para o ensino, assim como para a análise dos textos dos alunos-sujeitos pesquisados. No ensino, uma 
abordagem psicolinguística é também fundamental, principalmente, para se trabalhar numa perspectiva metacognitiva (o que fazemos quando lemos e quando escrevemos?). E a análise do discurso nos permite abordar elementos próprios às condições de produção dos gêneros nas práticas fora da sala de aula e na sala de aula, avaliando e compreendendo os fatores sócio-históricos que condicionam as práticas de produção e de recepção desses gêneros.

Os eventos de letramento que ocorrem nas salas de aula da universidade constituem matéria-prima importante para se compreender as práticas de letramento acadêmico. A partir de observações e análise de práticas de leitura e de escrita, em contextos de formação de professores, algumas perguntas orientam esse debate: quem, para que e como se ensina o gênero acadêmico, em cursos superiores para a formação de professores? com que imagens ou representações mentais sobre a interação acadêmica os alunos lidam nos momentos de leitura e de escrita? como se constroem essas representaçôes? quais são os conhecimentos prévios dos alunos sobre gêneros acadêmicos e em que medida são considerados ou ativados em situações de leitura e de escrita? que conhecimentos linguísticos e discursivos estão envolvidos na formação de habilidades e competências específicas dos gêneros acadêmicos, no campo da linguagem e da educação?

\section{A produção de resenha em um evento de letramento acadêmico}

Ao ouvir os depoimentos e acompanhar situaçóes de sala de aula de alunos da universidade em que trabalho, fica evidente que uma das dificuldades que eles enfrentam é a de entender que concepções e expectativas têm os seus professores quando lhes demandam uma tarefa de leitura ou de escrita. A concepção de resenha, de resumo, de fichamento - textos muito solicitados aos alunos - de um professor de Psicologia da Educação pode ser bem diferente daquela esperada por um professor de Didática ou de Filosofia. Da mesma forma que alguns estudos constataram que as crianças, nos primeiros anos de escolarização, vão aprendendo subliminarmente, por tentativas de acerto e erro, a responder adequadamente às atividades escolares que lhe são propostas, na universidade parece ocorrer o mesmo. Além de nem sempre o aluno ter uma concepção clara do que seja um determinado gênero, principalmente quando se trata de produção e não de leitura, também o professor não costuma explicitar de forma suficiente a sua concepção. Na maioria das vezes, ele apenas solicita "façam uma resenha, um fichamento, um artigo", supondo que esses conceitos são suficientemente claros e operacionais para que o aluno realize a sua tarefa. 
Em uma disciplina cujo objetivo é a produção de gêneros acadêmicos em educação, busca-se propor atividades que propiciem uma interação com objetivos sócio-comunicativos próprios aos usos sociais da escrita nas esferas de produção e circulação do conhecimento científico. Para tanto, o programa de curso, além de prever conhecimentos linguísticos, convenções e normas de produção desses textos, busca também discutir e compreender as condições de produção do discurso acadêmico. É necessário deslocar o aluno e o professor de determinadas pressupostos, convenções e acordos tacitamente estabelecidos, quando se realizam atividades nas disciplinas de curso superior, nesse caso em um curso de graduação em Pedagogia.

Foi solicitado aos alunos que produzissem uma resenha jornalística de uma conferência proferida por um professor de outra universidade. Posteriormente, foi feito um trabalho com a produção da resenha acadêmica. Pelo conteúdo dessa conferência, o destinatário da resenha seria o leitor de um jornal do curso de comunicação, produzido pelos próprios alunos, sob a orientação de professores. A indicação desse jornal (de fato existente) serviria como apoio para a construção da imagem de um leitor-modelo, já que a temática da conferência focalizava a mídia. Os alunos receberam um roteiro escrito com algumas orientações para a produção desse texto: 1) eles deveriam anotar, durante a conferência, informações relevantes, o ponto de vista adotado pelo conferencista, a tese por ele defendida, assim como os principais argumentos apresentados; 2) como era meu interesse ter acesso ao percurso ou estratégias utilizadas pelos alunos nesse processo, solicitei também que entregassem todos os rascunhos anteriores à versão final.

Analisando os escritos dos alunos, a discussão do trabalho em sala de aula e os seus textos, foi possível levantar três aspectos significativos que nos permitem problematizar as condições de produção do texto escrito nesse curso de graduação, os quais estão relacionados: 1) à concepção de linguagem e de gênero discursivo subjacentes a essas práticas; 2) aos conhecimentos e disposiçóes dos alunos sobre a língua escrita; 3 ) às estratégias ou procedimentos didáticos facilitadores da produção do texto escrito nesse contexto da sala de aula de um curso universitário.

A primeira revelação, quando fiz a leitura dos textos, foi a de que nenhum deles trazia uma resenha jornalística, todos eram o que se convencionou chamar de "trabalho de uma disciplina". Veremos a seguir o que era, nesse caso, um trabalho para a disciplina de Leitura e Produção de Gêneros Acadêmicos em Educação. 


\section{Desconstruindo o gênero "trabalho"}

$\mathrm{Na}$ aula subsequente à conferência, os alunos trouxeram o texto que, por suposto, teriam concebido como resenha jornalística e com ela os rascunhos. Algumas características comuns a esses textos me levaram à constatação de que eles não poderiam cumprir a sua função de resenha. Todos tinham uma folha de rosto (papel ofício), com o nome da universidade, da disciplina, do professor, do aluno, turma, local, data, etc. $\mathrm{O}$ trabalho aqui analisado contém quatro páginas. Nessa página de rosto, o autor nomeia o seu trabalho como sintese, e não como resenha. Numa segunda página, ele identifica o título da conferência e o conferencista. Na terceira página, aparece o primeiro tópico da orientação dada para o processo de produção da resenha. Embora não tenha um título, são as anotações organizadas a partir de dois rascunhos manuscritos. Um rascunho foi feito no momento da conferência e o segundo, em casa, antes da digitação final. Numa quarta página, o aluno-autor apresenta o gênero por ele escolhido, a "síntese" da conferência. $\mathrm{O}$ autor ajunta ainda mais duas páginas, nas quais ele cola os rascunhos, feitos em duas etapas (rascunho 1 e rascunho 2).

Li todo o material entregue, questionando se esse aluno (e também os outros) saberia ou não o que é uma resenha jornalística, mas com a certeza de que ele já tinha tido contato com esse gênero, por meio da mídia falada e escrita; no mínimo, com a resenha esportiva, já que era, declaradamente, um torcedor. Como, então, desconstruir essa concepção de "trabalho" de disciplina, que torna todos os textos muito semelhantes e não permitem que eles minimamente se aproximem dos gêneros produzidos nas práticas sociais de escrita? A universidade, os cursos de formação de professores estariam reproduzindo os mesmos "vícios" ou "erros" que tão bem apontamos nas práticas de escrita da escola do ensino médio e fundamental? Que razões nos levariam a isso?

Fiz algumas poucas anotações no seu trabalho, orientando a realização de uma nova versão do texto, com o objetivo principal de transformá-lo em uma resenha, tanto no seu conteúdo, na sua forma composicional ou estilística, quanto na sua apresentação gráfica. Busquei identificar o que havia naquele texto do aluno que pertencia ao gênero solicitado, separando o que estava sobrando ou que fazia parte do processo, a exemplo das anotações das duas páginas introdutórias (capa, página de rosto), mas não deveriam aparecer, pois eram apenas andaimes da obra final. Ali havia, sim, um texto (aquilo que o autor chamou de Sintese) cujo conteúdo poderia ser trabalhado com o propósito de se chegar a uma configuração textual e discursiva própria da resenha jornalística. 
Como a leitura e a análise de gêneros, nesse curso, fazem parte desse aprendizado, fizemos uma análise de algumas resenhas publicadas em jornais e revistas, chamando a atenção para a sua estrutura e estratégias enunciativas, que buscam seduzir o leitor, além de informar ou dar a conhecer sobre um acontecimento. Pelos textos apresentados posteriormente, foi possível perceber que os alunos tinham mais conhecimentos sobre o gênero do que, de fato, apresentaram nos textos produzidos. A justificativa dada por eles, quando interrogados por que não lançaram mão deles, foi a de que todo trabalho deve ter aquela forma apresentada e que nunca tinham sido solicitados a escrever uma resenha "com cara e com jeito de resenha”. Em resumo, não foi preciso fazer muito esforço para que, numa segunda versão, a maioria escrevesse uma resenha jornalística, mesmo com alguns problemas gramaticais ou de conteúdo.

Vejamos a primeira e a segunda versões de uma dessas resenhas, após algumas poucas intervençōes e perguntas feitas ao autor. Serão abordados alguns aspectos considerados mais relevantes para a discussão em foco:

\section{Primeira Versão}

II

Síntese

Para Sírio Possenti, do Instituto de Estudos da Linguagem - IEL/ UNICAMP, a imprensa, a mídia é preconceituosa por não discutir o fenômeno da linguagem. Aquilo que a imprensa passa como ortografia correta, como língua correta, guarda um fundo que o conferencista identifica e caracteriza como medieval. Isso porque a imprensa utiliza, muitas vezes, o dicionário como fonte, esquecendo-se que aí não estão todas as palavras existentes - conforme lei existente que ampara dicionários.

Possenti vê a aprendizagem de gramática como sendo programa para a vida inteira. Uma criança (hoje em dia) em seu processo de alfabetização, passa pelos mesmos erros que já possuíam os escrivinhadores do século XVIII. Na visão de um colunista, esta criança sempre estará errada pelo fato de suas palavras não existirem no dicionário - visão medieval. Um colunista não reconheceria que a criança está passando por uma fase de aquisição da tecnologia da escrita, onde teria que passar por algumas fases (garatuja, escrita pré-silábica, silábica, alfabética, etc.). Não teria o mesmo olhar de um educador.

Ele afirma ainda que "quem sabe ler, lê sem ponto, sem vírgula", isso porque o bom leitor já está dotado de estratégias que visam a facilitar o processo de leitura, tipo: previsão de leitura, supor o significado de determinadas palavras encontradas em um determinado contexto, etc. 
Ex.: se depararmos com a seguinte frase - Havia um sabia na bananeira. Sabemos que a palavra sublinhada trata-se de um pássaro, o sabiá. Já a imprensa consideraria o significado da palavra ao pé da letra e, de acordo com Possenti, iria rir.

"A imprensa peca um pouco em suas explicações. Não há tentativa de entender, mas sim de rir".

Afirma, ainda, que a imprensa segue uma linha purista, e aqui novamente erra. Nesse pensamento, a imprensa opōe-se à inovação, na tentativa de uma uniformização total (escrita, fala,etc.). Ela não considera que a linguagem deve ser utilizada de acordo com o ambiente em que nos encontramos. Claro, devemos saber que existe uma língua tida como culta, como padrão e que existe ocasiōes onde devemos usá-las.

O conferencista não deixa de reconhecer um certo valor à imprensa ao afirmar que "em colunas de jornal, tv, a pessoa pode aprender pelo fato de investir tempo" aproveitando a autoajuda, a solução fácil.

\section{Segunda Versão}

\section{RESENHA}

$$
\text { O "sabia" na bananeira }
$$

Nome do aluno-autor

Se você leu "sabiá", você leu corretamente. Como se pode observar no discurso do conferencista Sírio Possenti, do Instituto de Estudos da Linguagem - IEL / Unicamp, na conferência A língua na imprensa: Quem sabe ler, lê sem ponto e vírgula". Se tal frase fosse analisada pela mídia, o fenômeno da linguagem não seria discutido isto porque a imprensa guarda um fundo medieval, na visão do conferencista, visto que utiliza muitas vezes o dicionário como fonte de pesquisa para verificar se as palavras estão grafadas corretamente ou não.

Utilizando a visão de Possenti, vamos fazer alguns contrapontos:

Possenti vê a aprendizagem da gramática como sendo programa para a vida inteira.

Um criança (hoje em dia), em seu processo de alfabetização, passa pelos mesmos erros que já possuíam os escrivinhadores do séc. XVIII. Na visão de um colunista esta criança sempre estará errada pelo fato de suas palavras não existirem no dicionário - visão medieval. Um colunista não

"Quem sabe ler, lê sem ponto ou vírgula" 
reconheceria que a criança está passando por uma fase de aquisição da tecnologia da escrita, onde teria que passar por algumas fases (garatuja, escrita pré-silábica, silábica, alfabética, etc.) Não teria o mesmo olhar de um educador.

Ele afirma ainda que "quem sabe ler, lê sem ponto, sem vígula", isso porque o bom leitor já está dotado de estratégias que visam a facilitar o processo de leitura, a saber: previsão, inferências, etc. A frase com que iniciei minha resenha foi proposital. Sabia e não Sabiá. A imprensa levaria tal palavra ao pé da letra e, de acordo com Possenti, iria rir.

"A imprensa peca um pouco em suas explicações. Não há tentativa de entender, mas sim de rir".

Afirma, ainda, o professor Possenti, que a imprensa segue uma linha purista, e aqui novamente erra. Com esse pensamento, a imprensa opõe-se à inovação, na tentativa de uma uniformização total (escrita, fala, etc.). Tudo bem. Após todo esse discurso, cabe ao educador uma indagação: "Mas qual será o papel da escola diante desse contexto apresentado? Como a escola deve tratar a intervenção/correção que a imprensa faz? A escola é uma instituição onde a política do lessefer não pode ser adotada (pelo menos nas conjunturas atuais). É dado à escola o papel de ensinamento e é com a esperança de aprender que as crianças ali estão. Uma posição possível, talvez, seria considerar que a linguagem deve ser utilizada de acordo com o contexto em que nos encontramos, considerar que durante o processo de alfabetização o educando passa por algumas fases, mas que existe uma língua tida como culta e que devemos "dominá-la" ou pelo menos buscar seu domínio (e que certos momentos da vida será somente ela que utilizaremos). Não é meu objetivo discorrer sobre todas as posições que a escola possa via a tomar, cabe ao educador, ao professor encontrar a sua melhor maneira de lidar com o assunto. Qual seria sua posição?

O ponto de vista ou a perspectiva enunciativa de um discurso é fundamental para a definiçãao de um gênero e para o sucesso de uma interlocução. E essa foi uma das mudanças radicais entre o primeiro e o segundo texto. A começar pelo título, destaca-se o efeito produzido pela substituição de 'Sintese para ' $O$ "sabia" na bananeira', a paginação do texto em colunas, a indicação do nome do autor e até o uso de foto, recurso caro ao gênero jornalístico.

$\mathrm{Na}$ primeira versão, o autor opta pela $3^{\text {a }}$ pessoa do discurso, criando um efeito de distanciamento do autor (e também do leitor) em relação ao objeto resenhado e entre os interlocutores (autor-leitor). No início da primeira versão, o aluno-autor elege o conferencista e o tema como o ponto de apoio do texto. $\mathrm{Na}$ segunda, além de se intrometer ostensivamente no texto, lançando mão 
também da primeira pessoa do singular (iniciei minha resenha; meu objetivo), ele se dirige ao leitor, já no início do texto, convidando-o a participar dessa enunciação, instituindo um lugar de coenunciador (Se você leu sabiá, você leu corretamente), construindo uma parceria, por meio da primeira pessoa do plural (vamos fazer alguns contrapontos) e fechando com uma pergunta dirigida ao leitor (Qual seria sua posição?). Essa mudança vai instituir uma relação mais amigável e interativa com o leitor, o que é próprio de alguns gêneros, por exemplo, os jornalísticos.

Outras alterações foram feitas, visando a perspectiva de interação autor/ leitor. $\mathrm{O}$ enunciado Se depararmos com a seguinte frase - Havia um sabia na bananeira. Sabemos que a palavra sublinhada trata-se de um pássaro, o sabia foi substituído por A frase com que iniciei minha resenha foi proposital. Sabia e não Sabiá.

Mas nem tudo foi tão fácil assim. Duas tarefas foram mais difíceis: a compreensão de alguns aspectos do próprio conteúdo, já que o conferencista trouxe para esses alunos uma discussão não propriamente familiar a eles, e a análise e revisão de aspectos relacionados à coesão textual e à morfossintaxe. Uma terceira versão (não apresentada aqui) foi necessária para tratar desses aspectos. $\mathrm{O}$ texto apresenta problemas de interpretação ou de coerência em relação ao conteúdo exposto pelo conferencista. Isso pode significar que o aluno-autor não entendeu algum argumento do conferencista ou que ele quer agregar um outro argumento ao texto, até mesmo discordar, mas não é bemsucedido na identificação ou alternância de vozes presentes no seu discurso. Essa mistura de vozes, do conferencista e do resenhista, pode causar estranhamentos, por colocar na boca do conferencista algo que ele não proferiu. Isso pode revelar tanto uma dificuldade e estruturação sintática texto como também o desconhecimento de que essa é uma estratégia enunciativa importante, nesse contexto, manifestado nas atividades de reescrita comentadas que acompanhei na sala de aula.

Também pude observar (e não foi a primeira vez) que nem todas as mudanças da primeira para a segunda versão do texto são necessariamente mais adequadas. 


\section{Primeira Versão}

Aquilo que a imprensa passa como ortografia correta, como língua correta, guarda um fundo que o conferencista identifica e caracteriza como medieval. Isso porque a imprensa utiliza, muitas vezes, o dicionário como fonte, esquecendo-se que aí não estão todas as palavras existentes - conforme lei existente que ampara dicionários.

Utilizando a visão de Possenti, vamos fazer alguns contrapontos:

\section{Segunda Versão}

Se tal frase fosse analisada pela mídia, o fenômeno da linguagem não seria discutido isto porque a imprensa guarda um fundo medieval, na visão do conferencista, visto que utiliza muitas vezes o dicionário como fonte de pesquisa para verificar se as palavras estáo grafadas corretamente ou não.

\section{Conclusão}

Este trabalho levantou algumas questóes de interesse para o ensino e a pesquisa sobre as práticas de letramento acadêmico, desenvolvidas nos cursos de formação de professores na universidade. As reflexōes aqui apresentadas preconizam a necessidade de se desfazer crenças e pressupostos que dificultam uma relação mais positiva e produtiva dos estudantes universitários com a escrita acadêmica; de se desenvolver projetos de ensino e de pesquisa sobre essa temática. Algumas situações observadas indiciam uma relação tensa, conflituosa, nas interações mediadas pela escrita na universidade, o que nos leva a concluir que esse é um campo de produção de estigmas e de violência simbólica. Professores e alunos são vítimas de dificuldades que podem ser amenizadas se houver um investimento na compreensão dos problemas em torno dessa temática e em ações propositivas. O principal argumento para que seja dada maior atenção a essa problemática se apoia em uma concepção enunciativa da linguagem, especialmente na teoria dos gêneros de Bakhtin, para a qual o domínio de um gênero depende da experiência, da inscrição dos indivíduos nas esferas que os produzem e deles necessitam. Assim, o simples fato de o aluno ter sido aprovado no vestibular de uma boa universidade não garante que ele tenha familiaridade com os gêneros que lhe serão apresentados nas práticas acadêmicas. Um indivíduo pode ter bom domínio da língua, mas não necessariamente de todos os gêneros discursivos.

A partir de um evento de letramento - a produção de uma resenha jornalística - esta reflexão sugere que as atividades de escrita precisam ter fins pragmáticos, sócio-comunicativos específicos; que é necessário agenciar conhecimentos prévios desses alunos, propiciar o trabalho linguístico e 
metalinguístico do seu texto com atividades de reescrita comentadas. É importante também que eles compreendam as condições de produção do discurso acadêmico, as relações de poder neles envolvidas, de forma a não reduzir as suas dificuldades a uma suposta carência de conhecimentos linguísticos, gramaticais ou técnicos.

Uma perspectiva etnográfica de reflexão sobre a relação desses alunos com a escrita acadêmica permite ultrapassar o nível da análise dos textos, para se adentrar nas razões que explicam determinados comportamentos, atitudes e crenças que cercam o universo das relaçóes com a escrita no ambiente acadêmico. As disposiçôes mais ou menos favoráveis dos alunos para participarem de práticas de leitura e de escrita desses alunos dependem das estratégias pedagógicas agenciadas pelos professores das diversas disciplinas e de projetos pedagógicos voltados para esse conteúdo.

\section{Referências bibliográficas}

ATKINSON, D. The evolution of medical research writing from 1735-1985. Applied linguistics, v. II, p. 337-74, 1992.

BAKHTIN, M. Estética da criação verbal. São Paulo: Martins Fontes, 1997. (Trad. do francês Esthétique de la création verbal)

BARTON, D.; TUSTING, K. Beyond communities of practices. Cambridge: University Press, 2005.

BAZERMAN, C. Shaping written knowledge: the genre and activity of the experimental article in Science. Madison, Wisconsin: University of Wisconsin Press, 1988.

BOURDIEU, P.; PASSERON, J.-C.; MARTIN, M. Academic discourse : linguistic misundestanding and professional power. Trans. R. Teese. Cambridge: Polity Press, 1994.

BOUTET, Josiane. Écrits au travail. In: FRAENKEL, B. (Dir.). Illettrismes, variations historiques et anthropologiques. Paris: BPI-Centre Georges-Pompidou, 1993a. p. 253-266.

BOUTET, Josiane. Quelques proprietés des écrits au travail. Cahiers Langage et Travail, n. 6, p. 21-28, 1993 b.

CANDLIN, C. N.; PLUM, G. A. (Ed.). Engaging with the challenges of interdiscursivity in academic writing: researchers, students and tutors. In: CANDLIN, C. N.; HYLAND, K. (Ed.). Writing: texts, process and practices, London: Longman, 1999. p. 193-217. 
CANAGARAJAH, A. S. Safe house in the contact zone: coping strategies of AfricanAmerican students in the academy. College Composition and Communication, v. 48, p. 173-96, 1997.

CARVALHO, Figueiredo Débora; BONINI, Adair. Práticas discursivas e ensino do texto acadêmico: concepçôes de alunos de mestrado sobre a escrita. Linguagem em (Dis)curso - LemD, Tubarão, v. 6, n. 3, p. 413-446, set./dez. 2006.

CREME, P.; LEA, M. Writing at University. Buckingham: Open University Press, 2003.

FABRE, Daniel (Ed.). Par écrit. Ethnologie des écritures quotidiennes. Paris: Éditions de la Maison des Sciences de l'Homme, 1997.

FLOWERDEW, John. Introduction: approaches to the analysis of academic discourse in English. Academic discourse. London, Longman, p. 1-17, 2006.

FLOWERDEW, J.; MILLER, L. Lectures in a second language: notes towards a cultural grammar. English for Specific Purposes, v. 15, n. 2, p. 121-40, 1996.

FLOWERDEW. J., TAUROZA, $S$. The effect of discourse markers on second language lecture comprehension. Studies in Second Language Acquisition, 1995.

FRAENKEL, B. Enqueter sur les écrits dans l'organisation. In: FRAENKEL, B.; BORZEIX, A. Langage et travail: communication, cognition, action. CNRS, 2001. p. 210-261.

GRAFTON, Anthony. Les origines tragiques de l'érudition: une histoire de la note em bas de page. Traduit de l'anglais (américain) par Pierre-Antoine Fabre. Paris: Seuil, 1998.

GUNNARSSON, B. L. et al. (Ed.). The construction of professional discourse. London: Longman, 1997.

KAVAKAMA, Eveline Bouteiller. Fragmentos de um discurso acadêmico, 2001. Tese (Doutorado em Educação: Psicologia da Educação) - Programa de Estudos Pós-Graduados em Educação: Psicologia da Educação, Pontifícia Universidade Católica de São Paulo, SP, São Paulo, 2001.

LAHIRE, B. La raison des plus faibles: rapport au travail, écritures domestiques et lectures en milieux populaires. Paris: Presses Universitaires de Lille, 1993.

LAVE, J. Cognition in practice: Mind, mathematical and culture in everyday life. Cambridge: Cambridge University Press, 1998.

LAVE, J., WENGER, E. Situated learning: legitimate peripheral participation. Cambridge: Cambridge University Press, 1991.

MARINHO, Marildes. Tatu bota tumati: escrita, memória e formação do professor. In: PAULINO G.; COSSON, R. (Org.). Leitura literária, a mediação escolar. Belo Horizonte: FALE/UFMG, 2004, p. 29-38. 
MARINHO, Marildes. A cultura escrita em meios populares. In: GÓMES, Castillo Antonio (Dir.); BLAS, Verónica Sierra (Ed.). Mis primeiros pasos: alfabetizacion, escuela y usos cotidianos de la escritura (siglos XIX y XX). Gijón: Trea, 2008. p. 151-174.

MARINHO, Marildes. Lendo e escrevendo na academia: sobre o medo do estereótipo e da simplificação. In: GOMES, Nilma Lino; MARTINS, Aracy Alves (Org.). Afirmando direitos: acesso e permanência de jovens negros na universidade. Belo Horizonte: Autêntica, 2004. p. 189-198.

MARINHO, Marildes; CORAGEM, Amarilis Coelho; MACHADO, Maria Zélia Versiani; JORGE, M. L. S. Ler e escrever memórias: práticas de letramento no campo. In: ANTUNES-ROCHA, M. I.; MARTINS, A. A. (Org.). Educação do campo: desafio para a formação de professores. Belo Horizonte: Autêntica: 2009. v. 1, p. 119-138. MARTINS, Aracy A. Memórias de professores: eventos e práticas de literacia/ letramento. Revista Portuguesa de Educação, CIEd - Universidade do Minho, v. 18, n. 2, p. 185-213, 2005.

OLSEN, L. A.; HUCKIN, T. N. Point-driven understanding in engineering lecture comprehension. English for Specific Purposes, v. 9, p. 33-47, 1990.

PENNYCOOK, A. Borrowing others'words: text, ownership, memory, and plagiarism. TESOL Quartely, v. 30, n. 2, p. 201-30, 1996.

ROST, M. On-line summaries as representations of lecture understanding. In: FLOWERDEW, J. (Ed.). Academic listening: research perspectives, Cambridge: Cambridge University Press, 1994. p. 35-54.

SCHITINE, Silvania. A leitura de professores em um contexto de formação, 2003 Dissertação (Mestrado em Educação) - Faculdade de Educação, Universidade Federal de Minas Gerais, Belo Horizonte, 2003.

TAUROZA, S.; ALLISON, D. Expectation-driven understanding in informationsystems lecture comprehension. In. FLOWERDEW, J. (Ed.). Academic listening: research perspectives. Cambridge: Cambridge University Press, 1994. p. 35-54. VAN DIJK, T. A.; KINTSCH. W. Strategies of discourse comprehension. New York and London, 1983.

VAN LIER, Leo (1988). The Classroom and the Language Learner: Ethnography and Second Language Classroom Research. London; New York: Longman, 1998.

Recebido em setembro de 1009. Aprovado em dezembro de 2009. 